\title{
Isolation and characterization of an acrylamide-degrading yeast Rhodotorula sp. strain MBH23 KCTC 11960BP
}

\begin{abstract}
As well as for chemical and environmental reasons, acrylamide is widely used in many industrial applications. Due to its carcinogenicity and toxicity, its discharge into the environment causes adverse effects on humans and ecology alike. In this study, a novel acrylamide-degrading yeast has been isolated. The isolate was identified as Rhodotorula sp. strain MBH23 using ITS rRNA analysis. The results showed that the best carbon source for growth was glucose at $1.0 \%(\mathrm{w} / \mathrm{v})$. The optimum acrylamide concentration, being a nitrogen source for cellular growth, was at $500 \mathrm{mg} 1-1$. The highest tolerable concentration of acrylamide was $1500 \mathrm{mg} \mathrm{l}-1$ whereas growth was completely inhibited at $2000 \mathrm{mg} 1-1$. At

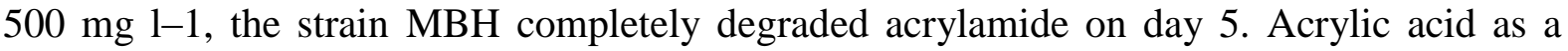
metabolite was detected in the media. Strain MBH23 grew well between $\mathrm{pH} 6.0$ and 8.0 and between 27 and $30{ }^{\circ} \mathrm{C}$. Amides such as 2-chloroacetamide, methacrylamide, nicotinamide, acrylamide, acetamide, and propionamide supported growth. Toxic heavy metals such as mercury, chromium, and cadmium inhibited growth on acrylamide.
\end{abstract}

Keyword: Acrylamide; Rhodotorula sp.; Acrylic acid 